\title{
La fiscalidad de la rehabilitación urbana en España
}

\author{
María LuiSa González-Cuéllar SERRANO*
}

Sumario. I. Introducción. El deber de los poderes públicos de fomentar la rehabilitación de edificios y viviendas. II. La fiscalidad como instrumento de los poderes públicos a favor de la rehabilitación urbana. III. El fomento de la rehabilitación en el impuesto sobre el valor añadido. 1. Los beneficios fiscales sobre la rehabilitación constructiva. IV. Ejecuciones de obra de renovación y reparación. V. La protección fiscal de la rehabilitación en el impuesto sobre la renta del particular. Referencias.

\section{Resumen}

El presente artículo hace un análisis de la normatividad alrededor de ciertos países de la Comunidad Europea sobre rehabilitación urbana. Los tributos sobre rehabilitación urbana encuentran su fundamentación en el derecho fundamental a la vivienda, y sobre todo, al mantenimiento de ciertos mínimos en la calidad de vida de los ciudadanos. La autora desarrolla los impuestos actualmente vigentes en España sobre la rehabilitación urbana, y establece una serie de recomendaciones, a partir del análisis comparado con países que introducen en su ordenamiento jurídico grabaciones similares.

\section{Introducción. El deber de los poderes públicos de fomentar la rehabilitación de edificios y viviendas}

El derecho a la vivienda es un derecho fundamental, recogido en la Declaración Universal de los Derechos Humanos (artículo 25.1). Por su parte, el artículo 47 de la Constitución española establece el derecho de todos los españoles a disfrutar de una vivienda "digna y adecuada". Al tratarse de un derecho de prestación, los poderes públicos están obligados a establecer las normas y actuaciones pertinentes para hacer efectivo este derecho.

Los adjetivos "digna y adecuada", referidos a la vivienda, determinan que el deber de las administraciones públicas no solo consiste en garantizar el acceso a una vivienda, sino en asegurar que esta cumple con

\footnotetext{
* Licenciada en Derecho por la Universidad Autónoma de Madrid (1992) y Doctora en Derecho por la Universidad Carlos III de Madrid (1997) (Premio extraordinario a tesis doctoral de la UC3M). Actualmente es profesora titular de Derecho Financiero y Tributario de la Universidad Carlos III de Madrid, y desde mayo de 2011 es Vicerrectora de Estudiantes y Vida Universitaria en la Universidad Carlos III de Madrid, España. Correo-e: marialuisa.gonzalez-cuellar@uc3m. es. Para citar el artículo: González-Cuéllar, M. (2016). "La fiscalidad de la rehabilitación urbana en España”. Revista de Derecho Fiscal n. ${ }^{\circ}$ 8, Bogotá: Universidad Externado de Colombia. pp. 67-85. DOI: http://dx.doi.org/10.18601/16926722.n8.06
} 
las condiciones necesarias de habitabilidad. En consecuencia, están obligadas a evitar el deterioro que sufren los inmuebles por el paso del tiempo y por el uso. En este sentido, la funcionalidad de los edificios no solo depende de la calidad inicial con la que se construyeron, sino también es fundamental su mantenimiento y conservación.

Sin embargo, en España, el objetivo de las políticas públicas ha sido tradicionalmente la construcción de nuevas viviendas, olvidando la necesidad de fomentar su mantenimiento y renovación. Esta tendencia se ha reflejado en las políticas fiscales, que se centran en la adquisición de vivienda nueva y en la reconstrucción integral de la vivienda deteriorada, olvidándose del incentivo a la mejora de las condiciones de habitabilidad. Así lo ponen de manifiesto los incentivos tributarios más importantes en este aspecto: la deducción en el Impuesto sobre la Renta de las Personas Físicas - IRPF (actualmente derogada), y la renuncia a la exención en el Impuesto sobre el Valor Añadido - IVA.

Esta tendencia debe cambiar y dirigirse al fomento de la renovación y al mantenimiento de las viviendas construidas. En otras palabras, es necesario pasar del incentivo a la construcción de viviendas (incluyendo su reconstrucción) y al fomento de la conservación y mejora de las viviendas ya existentes. Así se reconoce en diversos instrumentos normativos españoles, como la Ley 8/2013, de 26 de junio, de Rehabilitación, Regeneración y Renovación Urbanas, cuya exposición de motivos establece:

[e]l camino de la recuperación económica, mediante la reconversión del sector inmobiliario y de la construcción y también la garantía de un modelo sostenible e integrador, tanto ambiental, como social y econó- mico, requieren volcar todos los esfuerzos en aquellas actuaciones, es decir, las de rehabilitación y de regeneración y renovación urbanas que constituyen el objeto esencial de esta Ley. (...) España posee actualmente, si no se reactiva la demanda, suelo capaz de acoger nuevos crecimientos urbanísticos para los próximos cuarenta y cinco años. Esta situación se agrava cuando se observa que gran parte de estos suelos se encuentran situados en entornos donde no es previsible ningún incremento de demanda en los próximos años. A ello se une el dato significativo de vivienda acabada, nueva y sin vender (en torno a 680.000 viviendas). Tanto a corto, como a medio plazo, será muy difícil que los sectores inmobiliario y de la construcción puedan contribuir al crecimiento de la economía española y a la generación de empleo si continúan basándose, principalmente y con carácter general, en la transformación urbanística de suelos vírgenes y en la construcción de vivienda nueva.

Por otro lado, la Ley 18/2007, de 28 de diciembre, del derecho a la vivienda, de la CCAA de Cataluña, define la calidad de una vivienda como el conjunto de características y prestaciones que una vivienda debe tener para cumplir eficientemente su función social, las cuales deben adaptarse a los estándares de seguridad y confort adecuados en cada momento (artículo 22). Y reconoce que el fomento de la conservación, rehabilitación y gran rehabilitación del patrimonio inmobiliario residencial es objeto de la actuación prioritaria de la Generalidad y los entes locales para garantizar el derecho a una vivienda digna y adecuada" (artículo 29). En consecuencia, se establece de forma indubitada la obligación de la Administración de establecer medidas específicas para 
el fomento de la rehabilitación del parque de viviendas y de edificios de viviendas, tales como subvenciones directas, ventajas fiscales o actuaciones convenidas con propietarios o inquilinos (artículo 35).

Es importante constatar que más del 58\% del parque edificado español es anterior a 1980 y que el $50 \%$ del conjunto de viviendas en nuestro país (unos 12,5 millones) tiene más de 30 años, y cerca de 6 millones superan los 50 años. A pesar de estos datos, la rehabilitación en España supone un porcentaje muy bajo en relación con el total de la construcción: $28 \%$, teniendo en cuenta que en la media europea dicho porcentaje se sitúa en el 41,7\% (Exposición de Motivos Ley 8/2013, de 26 de junio).

Además del cumplimiento directo del mandato contenido en el artículo $47 \mathrm{CE}$, mediante la rehabilitación se alcanzan objetivos muy diversos, todos ellos muy necesarios en la consecución de una política social más igualitaria, una economía más saneada, una mejora medioambiental y una innovación tecnológica. Por ello, la actividad de la rehabilitación debe constituir un eje central de las políticas generales a favor del medio urbano sostenible, la eficiencia energética, la creación de empleo o la integración social de sectores de población desfavorecidos. En concreto:

1. La rehabilitación es un importante instrumento de cohesión social. Mediante la rehabilitación de edificios en condiciones degradadas, los poderes públicos posibilitan que colectivos con riesgo de exclusión social, en especial los inmigrantes, accedan a una vivienda digna. La vivienda es uno de los ámbitos clave para la adecuada integración de dichos colectivos, tanto desde una perspectiva individual (evitando el hacinamiento, el chabolismo y la infravivienda vertical), como desde una perspectiva colectiva (previniendo el establecimiento de guetos). Es evidente que la eliminación de barrios degradados, donde se agrupan los colectivos en riesgo de exclusión, condiciona todos los factores de integración social, en especial la inserción laboral y la educativa.

2. Se adecúan las viviendas y edificios a las condiciones de accesibilidad necesarias para personas con discapacidad. La Convención Internacional sobre los Derechos de las Personas con Discapacidad, aprobada en el seno de la ONU el 13 de diciembre de 2006, establece la obligación de los Estados miembros de adoptar las medidas necesarias para asegurar el acceso a los edificios de las personas con discapacidad (artículo 9.1).

3. Se mejora la eficiencia energética de los inтиebles, lo que ayuda a la lucha contra el cambio climático. En concreto, se potencia un mayor porcentaje de autoabastecimiento en consumos energéticos en viviendas y edificios y se evitan nuevos desarrollos urbanísticos. Un mantenimiento adecuado de los edificios evitará su demolición y la necesidad de construir uno nuevo cuando aquel pierda su funcionalidad. Y en los casos no deseables en que esta pérdida se produzca, contamina menos rehabilitar el edificio que demolerlo y construir uno nuevo. En palabras del Plan Estatal de fomento del alquiler de viviendas, la rehabilitación edificatoria y la regeneración y renovación urbanas, 2013-2016 (Plan Estatal 2013-2016, en adelante aprobado por Real Decreto 233/2013, de 5 de abril):

(...) estas actuaciones de rehabilitación de edificios y de regeneración y renovación urbanas, que inciden directamente sobre el ahorro y la eficiencia energética de las viviendas, son un elemento central en el esfuerzo por la instauración de una economía basada en bajas emisiones de carbono, 
de acuerdo con los objetivos del Gobierno y con las previsiones y políticas de la Unión Europea, que ayudará a reducir la factura energética de las familias y del país en su conjunto, así como a reducir las emisiones de gases de efecto invernadero.

\section{La rehabilitación es un sector económi-} co muy importante porque es especialmente intensivo en mano de obra. Se podría realizar una reconversión de los antiguos trabajadores de la construcción a la rehabilitación. Además tiene un impacto significativo sobre actividades relacionadas, como por ejemplo, el suministro de materiales. Así lo reconoce el Plan Estatal 2013-2016 cuando explica que el nuevo Plan incentiva al sector privado para que en términos de sostenibilidad y competitividad, y con soluciones y líneas de ayuda innovadoras, puedan reactivar el sector de la construcción a través de la rehabilitación, la regeneración y la renovación urbanas (Exposición de motivos Real Decreto 233/2013, de 5 de abril).

5. Esta relevancia para la economía se intensifica en relación con el sector turístico. Como establece la Exposición de Motivos del proyecto de Ley de rehabilitación, regeneración y renovación urbanas, la actividad turística es clave para la economía de nuestro país y supone más de un 10,2\% del PIB, aportando un 11,39\% del empleo. Numerosos destinos turísticos "maduros" se enfrentan a un problema sistémico en el que tiene mucho que ver el deterioro físico de sus dotaciones.

6. Con la rehabilitación de núcleos rurales se incentiva el repoblamiento de nuestros pueblos con la mejora que esto provoca en la actividad agrícola y ganadera de un país.

Centrándonos en la rehabilitación energética, es necesario ser conscientes de que el ámbito de la construcción es crucial en el debate sobre el cambio climático. El consumo energético en este sector supone el $40 \%$ del total de la energía que se consume en la Unión Europea, tal y como ha reconocido la Directiva 2012/27/UE, de 25 de octubre, relativa a la eficiencia energética. En nuestro país, el sector residencial representa, junto con el sector comercial e institucional, un $20 \%$ de las emisiones difusas.

Gracias al Paquete europeo de Energía y Cambio Climático, aprobado por la Unión Europea en diciembre de 2008, todos los Estados miembros deben alcanzar una reducción del $20 \%$ de las emisiones de gases de efecto invernadero, un $20 \%$ de energías renovables y mejorar la eficiencia energética en un $20 \%$. El cumplimiento de estos objetivos requiere, indiscutiblemente, el establecimiento de nuevas medidas en torno a la rehabilitación urbana.

Un paso indiscutible en este sentido ha sido la citada Directiva 2012/27/UE, que obliga a los Estados de la Unión Europea a mejorar el rendimiento energético de un porcentaje anual de los edificios de las Administraciones centrales mediante su rehabilitación, y a establecer una estrategia hasta el año 2020, en orden a movilizar inversiones en la renovación de edificios residenciales y comerciales. También hay que mencionar la Hoja de Ruta Energética 2050 (Informe elaborado por el Parlamento europeo y aprobado el 14 de marzo de 2013) que mantiene que la reducción del uso de la energía en los edificios debe ser un "elemento central" de la política energética de la Unión Europea a largo plazo, y pide una reducción del $80 \%$ del consumo energético de los edificios existentes en 2050, en comparación con los niveles de 2010 . 


\section{La fiscalidad como instrumento de los poderes públicos a favor de la rehabilitación urbana}

Una vez establecida la importancia del fomento por parte de los poderes públicos de la actividad rehabilitadora, hay que plantearse qué mecanismos son más eficaces en dicha consecución y, en concreto, la conveniencia de las medidas fiscales.

En cada momento, los poderes públicos adoptan los objetivos relativos a la política de vivienda que consideran más adecuados $\mathrm{y}$, en torno a ellos, articulan una serie de medidas necesarias para la consecución de aquellos. Junto a otros instrumentos, como las subvenciones o los créditos en condiciones preferentes, la normativa tributaria se viene considerando un complemento en la ejecución de la planificación de vivienda de cada momento.

Entre las medidas existentes en Europa como incentivo a la rehabilitación, la más extendida es la subvención. Estas presentan múltiples ventajas, frente a los incentivos fiscales, como su inmediatez (el particular recibe el dinero en tiempo actual, frente a los beneficios fiscales que se aplican normalmente en la declaración tributaria posterior); su aplicación a todos los niveles de renta (los beneficios fiscales solo se disfrutan por parte de los ciudadanos que obtienen renta $\mathrm{y}$, en consecuencia, presentan declaración tributaria); su aplicación por parte de órganos especializados en la materia (los beneficios fiscales se gestionan por técnicos de Hacienda, sin conocimientos específicos en vivienda), o su transparencia (la concesión de subvenciones es objeto de publicación, lo que provoca una información de la que no se dispone en relación con el impacto de los beneficios fiscales).
Pero también hay que ser conscientes de que, en ocasiones, dichas subvenciones no se emplean correctamente. Así lo ha expresado el Tribunal de Cuentas de la Unión Europea el 14 de enero de 2013 en relación con el mal uso que hacen los Estados miembros de las ayudas comunitarias previstas para mejorar la eficiencia energética (desde 2000, la Unión Europea ha asignado casi 5.000 millones de euros a la cofinanciación de estas medidas en los Estados miembros), ya que ninguno de los proyectos - examinados- incorporaba una evaluación de las necesidades ni un análisis potencial de ahorro energético en relación con las inversiones. Además, también criticaba que estas subvenciones se empleen mayoritariamente en la renovación de edificios públicos.

Junto a las subvenciones, también encontramos en la normativa europea beneficios fiscales a favor de los propietarios de viviendas que realizan inversiones de rehabilitación (en especial, energética), tanto en su impuesto sobre la renta como en su impuesto sobre la propiedad, o a favor del consumo de bienes y servicios que favorezcan una rehabilitación de los inmuebles. Una interesante comparativa de los instrumentos utilizados por diversos Estados miembros (Francia, Bélgica, Dinamarca, Alemania, Grecia, Países Bajos y Reino Unido) a favor de la promoción energética en edificios se presenta en el documento Applying the EPBD to improve the Energy Performance Requirements to Existing Buildings-ENPER EXIST, WP4: Roadmap for energy efficiency measures/policies in the existing building sector (Scientifique et technique du Batiment (CSTB), 2007).

En el gráfico siguiente puede apreciarse la diversidad de instrumentos empleados por los países de la Unión Europea y su grado de utilización: 


\section{Las ayudas públicas a la rehabilitación de edificios}

según nivel administrativo en la UE-27

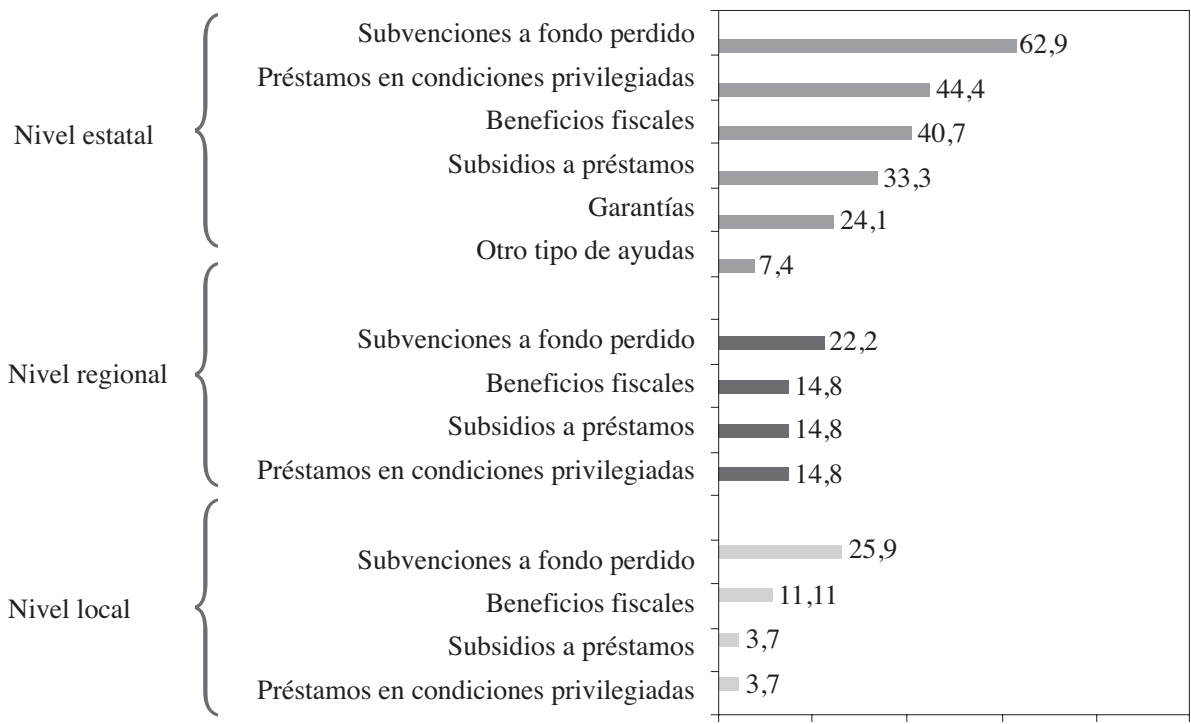

Fuente: Observatorio vasco de la vivienda, "Políticas de Rehabilitación y Regeneración Urbana en Europa. Informe ejecutivo", 2010. Ministerio de Vivienda, "La rehabilitación del parque residencial existente en la Unión Europea y otros países europeos", 2010.

En la opción entre las subvenciones y los beneficios fiscales resulta muy relevante en España la cuestión competencial. Como es sabido, el establecimiento de una subvención por parte de un ente territorial requiere un título competencial específico; de forma que solo cuando el ente-Estado, Comunidad Autónoma o Hacienda Local- ostente un título competencial sobre la materia, puede aprobar una subvención (STC 13/1992). Por el contrario, el Estado no está limitado por el ámbito competencial material en el establecimiento de tributos, de forma que puede crear un beneficio fiscal sobre una materia que no es de su competencia (STC 87/1987) (Casado Ollero, 1998, pág. 131). Esta cuestión, aunque es importante señalarla, no tiene gran incidencia en las actuaciones de fomen- to de rehabilitación de los núcleos urbanos, pues tanto el Estado como las CCAA tienen una competencia que pueden alegar en la implantación de ayudas directas (subvenciones) o indirectas (beneficios fiscales). El art. 148.1.3 atribuye a las CCAA la competencia en "ordenación del territorio, urbanismo y vivienda", lo que las legitima para ejecutar dicha competencia a través de cualquier tipo de ayuda. Por su parte, el Estado ostenta una competencia básica en vivienda en aras de garantizar la igualdad, según ha establecido el TC en su Sentencia 152/1988, de 20 de julio.

También resulta muy interesante comprobar cuáles son las actuaciones materiales que las Administraciones comunitarias tienden a financiar: 
Las ayudas públicas a la rehabilitación de edificios según nivel administrativo en la UE-27

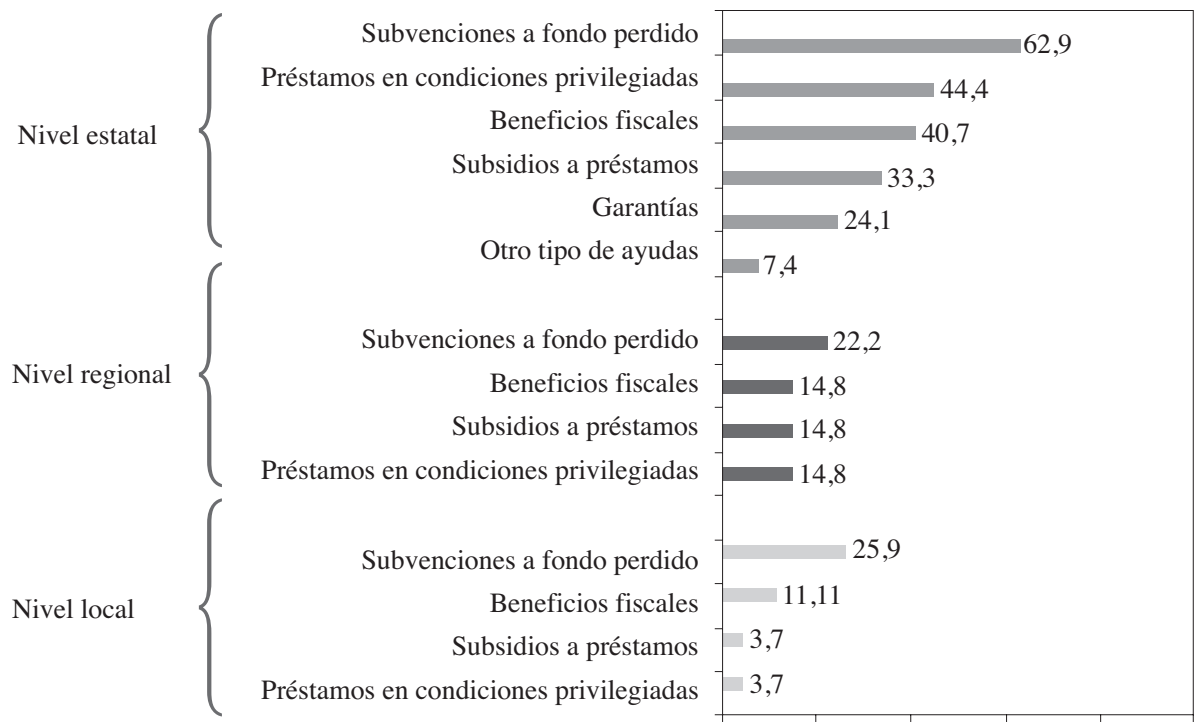

Fuente: Observatorio vasco de la vivienda, "Políticas de Rehabilitación y Regeneración Urbana en Europa. Informe ejecutivo", 2010. Instituto Universitario de Urbanística de la Universidad de Valladolid, "Regeneración urbana integrada en Europa", 2010.

Por otra parte, los beneficios fiscales a favor de la rehabilitación deben establecerse en los impuestos que afectan al particular, de forma que el gravamen sobre las obras de rehabilitación afecte lo menos posible su toma de decisión:

1. En el impuesto sobre la renta del particular que decide rehabilitar un inmueble de su propiedad. La mayor parte de los países europeos exige que dicho inmueble sea la vivienda habitual del particular (como fue el caso de España hasta que en 2012 desapareció la deducción), o del inquilino en caso de que el inmueble se encuentre alquilado (Francia).

\section{En el Impuesto sobre el Valor Añadido} - IVA. Diferentes Estados miembros (entre los que se encuentran España, Francia o Reino Unido) contemplan normas que be- nefician las operaciones de rehabilitación, en especial, haciéndolas tributar a un tipo de gravamen reducido.

3 . En los impuestos que gravan la propiedad (estableciendo una reducción cuando el inmueble goce de sistemas de ahorro energético, como ocurre en el Impuesto sobre Bienes Inmuebles español en relación con la instalación de sistemas para el aprovechamiento térmico o eléctrico de la energía solar) (Ley de Haciendas Locales artículo 45).

4. En los impuestos que gravan la realización de una obra en el inmueble de forma directa, estableciendo una menor fiscalidad cuando dichas obras consistan en actuaciones de renovación energética, tal y como dispone el Impuesto sobre Construcciones, Instalaciones y Obras español, en relación con la instalación de sistemas para el aprove- 
chamiento térmico o eléctrico de la energía solar (Ley de Haciendas Locales artículo 103.2).

La legislación española contempla diversos beneficios fiscales a favor de la rehabilitación. Podemos mencionar los siguientes hitos en la mejora de la fiscalidad de la rehabilitación:

a) Ampliación del concepto de rehabilitación estructural a efectos de la sujeción al IVA de las obras realizadas y de la aplicación del tipo de gravamen reducido. Esta extensión del concepto de IVA comenzó con el Real Decreto-Ley 2/2008, de 21 de abril, se continuó con el Real Decreto $861 / 2008$, de 23 de mayo, que reprodujo la ampliación del concepto de rehabilitación a efectos de IRPF, $y$ ha sido culminado con el Real Decreto-Ley 6/2010, de 9 de abril, que precisa el sentido del término "obras análogas".

b) Reducción del tipo de gravamen del IVA para las obras de renovación y reparación de vivienda. Las obras de rehabilitación y renovación de viviendas tributarán al 10\% (establecido por el Real Decreto-Ley 6/2010).

c) Deducción temporal en el IRPF por obras de mejora de la vivienda habitual: implantada por el Real Decreto-Ley 6/2010 y cuya vigencia ya ha finalizado.

d) Integración de las actividades de rehabilitación en el objeto social de las Sociedades Anónimas Cotizadas de Inversión en el Mercado Inmobiliario, creadas por la Ley 11/2009, de 26 de octubre.

Sin embargo, en los últimos años se ha producido en España un retroceso en la protección fiscal de la rehabilitación de inmuebles, al eliminar la deducción por inversión en vivienda habitual en el Impuesto sobre la Renta de las Personas Físicas, sin tener en cuenta que dentro de esta deducción se integraba la relativa a las actuaciones de rehabilitación.

En los siguientes epígrafes analizamos los distintos ámbitos en los que es más conveniente la implantación de beneficios fiscales que incentiven la rehabilitación de las viviendas y edificios, en especial la tendente a alcanzar una mejora energética: a) el IVA, y b) en el impuesto sobre la renta del particular que decide rehabilitar.

Es importante destacar que los beneficios fiscales a favor de la rehabilitación no se basan en el principio de capacidad económica, sino en la protección de otros fines no tributarios, ya mencionados anteriormente. Y desde ese parámetro de eficacia en la consecución de estos objetivos deben ser analizadas. Esta constatación provoca, por ejemplo, que no sea inconstitucional que las deducciones a favor de la rehabilitación no se modulen en función del nivel de renta del contribuyente: si el fundamento de esta deducción reside en el incentivo a la rehabilitación, debe otorgarse exclusivamente en función del importe gastado en la rehabilitación.

\section{El fomento de la rehabilitación en el impuesto sobre el valor añadido}

El Anexo III de la Directiva 2006/112/CE del Consejo, de 28 de noviembre de 2006, relativa al sistema común del Impuesto sobre el Valor Añadido, incluye dentro de la lista de entregas de bienes y prestaciones de servicios que podrán estar sujetas a los tipos reducidos del IVA, el "suministro, construcción, renovación y transformación de viviendas proporcionadas en el marco de la política social".

Se trata de un enunciado de interpretación dudosa por dos motivos. En primer lugar, 
la Directiva no recoge un concepto de renovación o transformación; esta ausencia provoca que cada Estado miembro contemple un concepto diferente de rehabilitación a efectos de la aplicación de los beneficios fiscales en IVA. En segundo lugar, vincula el beneficio a que la actividad sea parte de una política social. La Comisión, consciente de este problema interpretativo por parte de los diferentes Estados miembros, autoriza expresamente que se admita la aplicación de un tipo reducido en el IVA a todo el sector de la construcción, y propone la extensión del supuesto establecido en la Legislación comunitaria a los siguientes: a) provisión, construcción, renovación y alteración de las viviendas, como partes de la política social; los Estados miembros pueden también aprobar una tarifa reducida para aquellas actividades relativas a la vivienda que no formen parte de la política social" (European Commission, TAXUD/D1 D/24232, 6).

Dentro de esta cláusula de la Sexta Directiva se han integrado dos tipos de ejecuciones de obras: la rehabilitación integral propiamente dicha del edificio, y las obras de renovación y reparación.

a) Rehabilitación: se trata de una rehabilitación constructiva, en el sentido de que da lugar a un edificio estructuralmente reforzado. Por ello, se equipara con la construcción de vivienda: la entrega del edificio rehabilitado está sujeta a IVA (no se considera segunda entrega, lo que provocaría su sujeción al Impuesto sobre Transmisiones Patrimoniales, TPO en adelante) y las actuaciones de rehabilitación tributan al tipo de gravamen reducido.

b) Las obras de renovación y mejora (como la albañilería, la pintura o la fontanería) dentro de la vivienda tributan al tipo de gravamen reducido.

\section{Los beneficios fiscales sobre la rehabilitación constructiva}

La tributación de una obra será diferente según se califique por el ordenamiento interno como rehabilitación o no. La mayoría de los países europeos contemplan dos consecuencias fiscales para las actuaciones de rehabilitación: la equiparación de la transmisión del inmueble rehabilitado con la venta del inmueble nuevo a efectos de su sujeción al IVA (como no se considera una segunda transmisión de la edificación no se encuentra exenta de IVA y, por consiguiente, sujeta a TPO) y la aplicación de un tipo de gravamen reducido a las actuaciones de rehabilitación.

Antes de entrar en el análisis de estos dos beneficios fiscales, es necesario plantearse el concepto de rehabilitación en el IVA.

\section{a. Concepto de rehabilitación}

Como se ha mencionado anteriormente, no existe un concepto de rehabilitación en la Directiva comunitaria, de forma que cada país engloba diversas actuaciones dentro de este concepto a efectos de atribuirle los beneficios fiscales en el IVA.

Sin embargo, en la XVIII Reunión Informal de Ministros responsables de Vivienda de la Unión Europea (Toledo, 21 de junio de 2010) sí se llegó a un consenso sobre el concepto de rehabilitación tanto de viviendas como de edificios en los siguientes términos: la rehabilitación de viviendas es el conjunto de actuaciones necesarias para mejorar las condiciones de habitabilidad, la eficiencia energética, la protección del medio ambiente, la utilización de energías renovables y la accesibilidad física a la vivienda. Por su parte, la rehabilitación de edificios consiste en el conjunto de actuaciones necesarias 
para mejorar las condiciones estructurales del edificio, la eficiencia energética, la protección del medio ambiente, la utilización de energías renovables, y los aspectos arquitectónicos y para garantizar su seguridad y estanqueidad (Informe Rehabilitación Parque Residencial - Toledo, 2010, pág. 8).

En España, durante mucho tiempo, la legislación fiscal relativa al IVA ha mantenido una visión meramente estructural de la rehabilitación. En concordancia con esta concepción, los beneficios aplicables a la rehabilitación solo se disfrutaban por aquellas obras que supusiesen exclusivamente una reforma estructural del edificio.

En este sentido, el artículo 20.Uno.22 LIVA, entendía por obras de rehabilitación de edificaciones las que tienen por objeto principal la reconstrucción de las mismas mediante la consolidación y el tratamiento de las estructuras, fachadas o cubiertas y otras análogas, siempre que el coste global de las operaciones de rehabilitación exceda del 25\% del precio de adquisición. La Dirección General de Tributos realizaba una interpretación muy estricta de los elementos sobre los que es posible realizar una rehabilitación, limitando su ámbito a los estructurales. Así entendía por "análogas", por ejemplo, las destinadas a la consolidación y saneamiento de los cimientos de la edificación, o los drenajes efectuados para preservar los muros de humedad (RDGT 11/9/2006 V1818-06, RTEAC 12 de enero de 2000, 18 de febrero de 2000, 17 de marzo de 2003).

Este concepto ha ido cambiando a lo largo de los últimos años, hasta llegar actualmente a una visión de la rehabilitación "fiscal" más acorde con la arquitectónica. La ampliación del concepto de rehabilitación en España es fruto de un largo proceso legislativo, que se inició con Real Decreto-Ley 2/2008, de 21 de abril; de medidas de impulso a la actividad económica, y que empezó modificando el concepto de "rehabilitación" contenido en la Ley del Impuesto sobre el Valor Añadido y de la Ley del Impuesto General Canario, en el sentido de que se descuente del precio de adquisición o del valor de mercado de la edificación la parte proporcional correspondiente al suelo. Por su parte, el Real Decreto $861 / 2008$, de 23 de mayo, también modificó el Reglamento del Impuesto sobre la Renta de las Personas Físicas para incorporar la citada regulación.

En definitiva, en España, una ejecución de obra se consideraba rehabilitación cuando se daban los siguientes requisitos:

Requisito cuantitativo: El coste de la obra debe superar el $25 \%$ del valor de adquisición o del valor de mercado del edificio (dependiendo de que la adquisición se produzca durante los dos años inmediatamente anteriores al inicio de las obras de rehabilitación o después). De dicho cómputo es necesario excluir el valor del suelo, según dispuso el Decreto-Ley 2/2008, de 21 de abril (Falcón y Tella, en Quincena fiscal, n. ${ }^{\circ}$ 12, 2008, pág. 10). El autor aboga por reducir el porcentaje del $25 \%$ al $20 \%$, para equipararlo con el contemplado en el artículo 8.Dos.1.
Requisito cualitativo: El Decreto-Ley 2/2008 también introdujo la mención de que la reconstrucción del inmueble constituya el objeto principal de la rehabilitación.

- El objeto principal de las actuaciones debía ser la reconstrucción del edificio. En las obras de contenido complejo este requisito se cumplía cuando más del $50 \%$ del coste total del presupuesto eran actuaciones de consolidación, tratamiento de las estructuras, fachadas o cubiertas u obras análogas (ampliación de la superficie construida, instalación de ascensores, entre otros) o conexas (obras de fontanería, albañilería, carpintería, incorporación de energías renovables, entre otros).

Es decir, se admitía que en el proyecto en su conjunto tuvieran cabida otras obras que no eran rehabilitación estructural si su coste no alcanzaba el $50 \%$ del total. 
Pero este concepto, limitado a un enfoque parcial de rehabilitación de elementos estructurales, fue actualizado por el Real Decreto-Ley 6/2010, de 9 de abril. El legislador ha sido consciente de que estaba manteniendo una visión arcaica de la rehabilitación, limitándola casi exclusivamente a la rehabilitación de los aspectos estructurales de los edificios existentes. En un primer momento tenía como objetivo principal contrarrestar el paso del tiempo sobre el edificio o mantenerlo en condiciones de seguridad estructural y estabilidad alejándolo de la ruina física.

Superada esta visión inicial en el ámbito arquitectónico de la actuación rehabilitadora "estructural" del edificio, hoy día se acepta que un edificio puede seguir siendo inservible para el uso previsto por razones diferentes de la seguridad estructural. En consecuencia, el edificio puede requerir rehabilitación para adecuarlo al uso previsto.

Por ello, un concepto amplio de rehabilitación desde el punto de vista constructivo ha de entenderse comprensivo de muchas actuaciones que forman parte de las técnicas constructivas para reponer al edificio en las condiciones necesarias para ser útil y funcional para el uso previsto.

Deben dejarse de lado, en el concepto de rehabilitación, aquellas actuaciones que se realicen en fachadas con la sola pretensión de mejorar aspectos de acabado, revoco, pintura o mero mantenimiento de los elementos de una fachada. Estas actuaciones configuran lo que se ha venido a denominar el "ornato".

Por lo tanto, tras la redacción dada por el Real Decreto-Ley 6/2010, de 9 de abril, el artículo 20.Uno.22 de la Ley 37/1992, de 28 de diciembre (en adelante, LIVA), se ha ampliado sustancialmente el concepto de re- habilitación, equiparándolo en gran medida al concepto de rehabilitación contenido en la normativa técnica (en especial el Código Técnico de la Edificación). Se consideran obras análogas a las de rehabilitación las siguientes actuaciones:

a) Las de adecuación estructural que proporcionen a la edificación condiciones de seguridad constructiva, de forma que quede garantizada su estabilidad y resistencia mecánica.

b) Las de refuerzo o adecuación de la cimentación, así como las que afecten o consistan en el tratamiento de pilares o forjados.

c) Las de ampliación de la superficie construida, sobre y bajo rasante.

d) Las de reconstrucción de fachadas y patios interiores.

e) Las de instalación de elementos elevadores, incluidos los destinados a salvar barreras arquitectónicas para su uso por discapacitados.

Por su parte, se consideran obras conexas a las de rehabilitación las que se citan a continuación, siempre que su coste total sea inferior al derivado de las obras de consolidación o tratamiento de elementos estructurales, fachadas o cubiertas y, en su caso, de las obras análogas a estas, siempre que estén vinculadas a ellas de forma indisociable y no consistan en el mero acabado u ornato de la edificación ni en el simple mantenimiento o pintura de la fachada, como:

a) Las obras de albañilería, fontanería y carpintería.

b) Las destinadas a la mejora y adecuación de cerramientos, instalaciones eléctricas, agua y climatización y protección contra incendios.

c) Las obras de rehabilitación energética. Se consideran obras de rehabilitación energética las destinadas a la mejora del 
comportamiento energético de las edificaciones reduciendo su demanda energética, al aumento del rendimiento de los sistemas e instalaciones térmicas o a la incorporación de equipos que utilicen fuentes de energía renovables.

\section{b. Régimen jurídico}

La diferencia en la tributación en España según se califique una actuación como rehabilitación o no es la siguiente:

Si se califica como rehabilitación, se les da el mismo régimen fiscal que a las obras de edificación:

a) Las entregas de edificaciones que se produzcan después de la rehabilitación de las mismas se considera primera entrega de edificación, sujeta y no exenta del IVA. Las dos consecuencias de esta medida son: la sujeción a IVA (no sujeción al TPO) y la posibilidad de deducir las cuotas de IVA soportadas tanto en la adquisición como en la rehabilitación del inmueble. En este caso, hay que tener en cuenta la inversión del sujeto pasivo que aprobó la Ley 7/2012, de 29 de octubre (artículo 5) para los supuestos de ejecuciones de obra, con o sin aportación de materiales, así como las cesiones de personal para su realización, consecuencia de contratos directamente formalizados entre el promotor y el contratista que tengan por objeto la urbanización de terrenos o la construcción o rehabilitación de edificaciones.

b) En el caso de que los inmuebles rehabilitados sean aptos para su utilización como vivienda, en su entrega se aplica el tipo de gravamen del $10 \%$ o el $4 \%$ en función de la calificación de la vivienda.

c) Las obras de rehabilitación tributan al $10 \%$. d) Las entregas de edificaciones para ser objeto de rehabilitación inmediata también están sujetas y no exentas.

Si las obras no se califican como rehabilitación:

a) Las entregas de los edificios sobre los que se ha actuado están sujetas y exentas del IVA. Las dos consecuencias de esta medida son: la sujeción a TPO y la imposibilidad de deducir las cuotas de IVA soportadas en la adquisición o en las obras efectuadas.

b) Las obras efectuadas tributan al $21 \%$.

Ausencia de exención en la transmisión del edificio rehabilitado:

La calificación de una obra como rehabilitación supone que la entrega posterior del edificio se considere primera entrega, con los efectos que ello tiene en relación con la ausencia de exención de la operación.

La equiparación de la venta del inmueble rehabilitado con la del inmueble nuevo significa que no se aplica la exención prevista en los ordenamientos tributarios para la entrega de segundas edificaciones. Así, por ejemplo, la Ley 37/1992 establece la exención de "las segundas y ulteriores entregas de edificaciones, incluidos los terrenos en que se hallen enclavadas, cuando tenga lugar después de terminada su construcción o rehabilitación" (artículo 20.Uno.22 LIVA).

A estos efectos, se considera primera entrega la realizada por promotor que tenga por objeto una edificación cuya construcción o rehabilitación ya esté terminada.

La ausencia de exención beneficia al empresario-rehabilitador transmitente que tiene derecho a deducirse las cuotas de IVA soportadas en la ejecución de obra para la rehabilitación. 


\section{Aplicación de tipo de gravamen reducido:}

Por lo que respecta al tipo de gravamen aplicable, como se mencionaba anteriormente, el Anexo III de la Directiva 2006/112/CE del Consejo, de 28 de noviembre de 2006, relativa al sistema común del IVA, incluye dentro de la lista de entregas de bienes y prestaciones de servicios que podrán estar sujetas a los tipos reducidos del IVA, el "suministro, construcción, renovación y transformación de viviendas proporcionadas en el marco de la política social".

En desarrollo de esta autorización comunitaria, el artículo 91.Uno de la Ley española sobre el IVA establece, entre los supuestos de aplicación del tipo reducido de IVA (10\%), el siguiente:

Las ejecuciones de obras, con o sin aportación de materiales, consecuencia de contratos directamente formalizados entre el promotor y el contratista que tengan por objeto la construcción o rehabilitación de edificaciones o partes de las mismas destinadas principalmente a viviendas (...) y cuyo coste global de las operaciones de rehabilitación exceda del $25 \%$ del precio de adquisición, si éste se hubiese efectuado durante los dos años inmediatamente anteriores, o del verdadero valor de la edificación.

De esta forma, la aplicación del tipo de gravamen reducido requiere la concurrencia de los requisitos establecidos en el artículo 20.Uno.22 LIVA.

Por su parte, el artículo 91, apartado uno.1, número 6 , declara que se aplicará el tipo impositivo del $10 \%$ a las entregas, importaciones y adquisiciones intracomunitarias de aparatos y complementos que, objetivamente considerados, sean suscepti- bles de destinarse esencial o principalmente a suplir las deficiencias físicas del hombre o de los animales, incluidas las limitativas de su movilidad y comunicación. Los artículos que por sus características objetivas están diseñados para facilitar la movilidad de personas con minusvalía (como salvaescaleras y rampas, entre otros), y son, por tanto, susceptibles de destinarse esencial o principalmente para suplir las deficiencias físicas de dichas personas, tributarán por el IVA al tipo del 10\%, con independencia de quien sea el que efectúe dichas entregas (el fabricante o una empresa comercializadora) o quien sea el adquirente del mismo (una persona con minusvalía o cualquier otra persona o entidad) (Resolución de la Dirección General de Tributos, de 11 de septiembre de 2006).

\section{Ejecuciones de obra de renovación y reparación}

En algunos países comunitarios (como España, Francia o el Reino Unido), las ejecuciones de obra de renovación y reparación realizadas en edificios o partes de los mismos destinados a viviendas, tributan al tipo de gravamen reducido del IVA.

En concreto, en España, el Real DecretoLey 6/2010 aprobó la aplicación de gravamen reducido para todo tipo de obras de renovación y reparación de viviendas realizadas desde el 14 de abril de 2010 hasta el 31 de diciembre de 2012. Posteriormente, el Real Decreto-Ley 20/2012, de 13 de julio, da medidas para garantizar la estabilidad presupuestaria y el fomento de la competitividad, y permite ampliar este límite temporal con vigencia indefinida. Así las cosas, tributan al $10 \%$ cuando se cumplan los siguientes requisitos (artículo 91.Uno.2.10): 
- Destinatarios: personas físicas y comunidades de vecinos que no actúen como empresarios o profesionales y utilicen la vivienda a que se refieren las obras para su uso particular.

- Inmueble: la construcción o rehabilitación de la vivienda a que se refieren las obras debe haber concluido al menos dos años antes del inicio de estas últimas.

- Materiales: la persona que realiza las obras no debe aportar materiales para su ejecución o, en el caso de que los aporte, su coste no excederá del 33 por 100 de la base imponible de la operación. En relación con la antigua deducción para obras de albañilería, la Administración entendía que debían considerarse "materiales aportados" todos aquellos bienes corporales que, en ejecución de las obras, queden incorporados materialmente al edificio, directamente o previa su transformación, tales como los ladrillos, arena, yeso, entre otras (Resolución de la Dirección General de Tributos de 11 de septiembre de 2006).

Con esta modificación, se extiende la aplicación del tipo reducido, hasta ahora limitado a las obras de albañilería, a todo tipo de obras de renovación y reparación, como, por ejemplo, fontanería, carpintería, electricidad, pintura, escayolistas e instalaciones y montajes.

Por su parte, Francia prevé la aplicación del tipo reducido del $7 \%$ a todos los trabajos de mejora, mantenimiento, transformación y acondicionamiento de las viviendas habituales adquiridas con una antigüedad superior a dos años (Loi 2012-1510 du 2012, artículo 68). La ampliación de las actuaciones que disfrutan del tipo reducido llega al punto de englobar las obras de urgencia aunque no se cumpla el requisito temporal que se acaba de mencionar (por ejemplo, las cañerías rotas).
La regulación francesa contiene precisiones que podríamos importar en España, como, por ejemplo:

- Se permite que algunas casas se encuentren vacías, siempre que el destino general del inmueble sea la vivienda habitual de sus ocupantes.

- Si el edificio no está afectado en su totalidad a la vivienda habitual:

- Si está afecto en más de un 50\%, el tipo de gravamen reducido se aplica a todos los trabajos.

- Si está afecto en menos de un 50\%, el tipo de gravamen reducido solo se aplica a los trabajos realizados sobre la parte del edificio destinada a vivienda habitual.

- El tipo de gravamen del 7\% se aplica no solo sobre el coste de la mano de obra directamente ligada a la ejecución de estos trabajos, sino que se extiende también a los materiales que sean suministrados por el prestador, como los equipos sanitarios y de calefacción, las puertas y ventanas, los equipos de seguridad y electrónicos.

- Asimismo, disfrutan del tipo del 7\% las prestaciones de estudio ligadas a la rehabilitación. Frente a la limitación establecida en la Ley española del IVA, que solo contempla la sujeción al 10\% de las ejecuciones de obras ligadas a la rehabilitación. Sería conveniente incluir en este tipo de gravamen también las prestaciones de servicios, como, por ejemplo, los proyectos de arquitectura, los estudios geotécnicos, la ejecución de un plan de seguridad, entre otros aspectos.

Para acabar con la somera descripción de la regulación francesa, es importante destacar que para beneficiarse del tipo de gravamen del $7 \%$, el cliente debe darle al prestador un certificado firmado y datado, antes del inicio de los trabajos, y como muy tarde en el 
momento de la factura o de la conclusión de los trabajos. Dicho certificado debe acreditar que el inmueble se adquirió hace más de dos años, que se utiliza como vivienda habitual y que los trabajos no dan lugar a la producción de un edificio nuevo.

Aparte de acoger en Derecho español las puntualizaciones del Derecho francés que acabamos de detallar, también podría proponerse extender la aplicación de tipo de gravamen reducido del $10 \%$ a las obras de renovación y reparación que se realizan en cualquier inmueble, con independencia de que sea la vivienda habitual del destinatario de la operación.

Por su parte, el Reino Unido contempla un tipo de gravamen reducido (5\%) para los materiales de ahorro de energía e instalaciones en viviendas, tales como aislamiento de paredes, suelos, bombas de calor, paneles solares, turbinas de agua (VAT ACT 1994, Section 29A. Notice 708/6 de 2001). Sin embargo, la Comisión Europea le ha denunciado ante el TJCE porque considera que la Directiva IVA no permite un tipo de IVA reducido para todos los materiales de ahorro de energía sin formar parte de una política social de vivienda.

Enlazando con la aplicación en el Reino Unido de un tipo de gravamen en el IVA muy reducido (5\%) para las obras de rehabilitación enmarcadas en la política de ahorro energético o de accesibilidad, es importante resaltar que la verdadera apuesta por una mejora de los edificios en su eficiencia energética y de accesibilidad, reclama la aplicación de un beneficio fiscal tangible, como es la aplicación del tipo de gravamen súper reducido a estas concretas obras de rehabilitación.

La Estrategia Española de Cambio Climático y Energía Limpia (Horizonte 2007-20122020) define como principales objetivos en el sector residencial, entre otros, la mejora de la eficiencia energética en los edificios y la promoción de medidas que incidan sobre el comportamiento del consumidor. $Y$ entre las principales medidas de la Estrategia se recoge "fomentar actuaciones de aumento de eficiencia energética de edificios antiguos mediante subvenciones o incentivos (a nivel nacional o autonómico)". Pues bien, la fiscalidad es una de las medidas con más influencia en la modulación de la toma de decisiones por parte de los consumidores.

Además, la aplicación de un tipo de gravamen muy reducido (que en España sería el 4\%) no plantearía problemas por parte del Derecho comunitario. Como ya ha sido expuesto, la Directiva 2006/112/CE del Consejo admite la aplicación de tipos reducidos a la renovación y transformación de viviendas. En febrero de 2009, en ECOFIN, en desarrollo de la Comunicación de la Comisión de noviembre de 2008 en la que se proponía la aplicación de un tipo de IVA reducido para los productos y servicios dirigidos a mejorar la eficiencia energética de los edificios (Commision of the European Communities, Bruselas, 2008, 15), acordó la posibilidad de que todos los Estados miembros tuvieran la opción de aplicar un IVA reducido a la reparación y renovación de viviendas particulares, excluidos los materiales que representen una parte significativa del valor del servicio suministrado (Reduced VAT rates: Draft agreement with a view to responding to the European Council, 2009). En concreto, en noviembre de 2008, la Comisión realizó una comunicación al Consejo en la que proponía medidas que favorecieran "la rápida implantación de los productos verdes", entre las que se encontraba la aplicación de un tipo de IVA reducido para los productos y servicios dirigidos a mejorar la eficiencia energética 
de los edificios (Commision of the European Communities, Bruselas, 2008, pág. 15).

\section{La protección fiscal de la rehabilitación en el impuesto sobre la renta del particular}

El mecanismo adecuado en el ámbito del impuesto personal sobre la renta del particular es la deducción en la cuota de un porcentaje del importe invertido en la rehabilitación del inmueble. Así se ha establecido en diversos países, como el Reino Unido o Francia.

Antes de exponer la situación legal en dichos países, hay que señalar que en España no existe actualmente ningún beneficio fiscal aplicable sobre el impuesto sobre la renta del particular que ha decidido rehabilitar, con la excepción de la deducción por obras de adecuación a una discapacidad. En este sentido, se recoge la deducción por obras e instalaciones de adecuación a la discapacidad en la vivienda habitual del contribuyente por razón de su propia discapacidad, de su cónyuge o un pariente hasta el tercer grado, inclusive que conviva con él (LIRPF artículo 68.1.4) También se otorga para los copropietarios de un inmueble en el que se realicen obras de modificación de elementos comunes del edificio o aplicación de dispositivos electrónicos que sirvan para suprimir barreras. En mi opinión, debería ampliarse el ámbito de sujetos pasivos que disfrutan de la deducción por realización de obras e instalaciones de adecuación de la vivienda para la accesibilidad de personas con discapacidad a cualquier propietario que tenga arrendado el inmueble a una persona con discapacidad con el objeto de ser la vivienda habitual de este y asuma los gastos derivados de dichas actuaciones.

La ausencia de un beneficio general para los gastos de rehabilitación es consecuencia de la eliminación de la deducción por inversión en vivienda habitual, para las adquisiciones de viviendas que se realizaran a partir del 1 de enero de 2013, por la Ley 16/2012, de 27 de diciembre.

En la práctica, esta derogación ha significado también la eliminación del beneficio fiscal a las obras de rehabilitación, dado que la deducción por rehabilitación se encontraba integrada en aquella. Este perjuicio no se habría producido si el legislador hubiera independizado hace tiempo la deducción por rehabilitación de la deducción por adquisición. En realidad, incluso cuando existía la deducción por inversión en vivienda habitual, la inclusión de la adquisición y de la rehabilitación dentro de una misma deducción provocaba la ineficacia de este beneficio fiscal en relación con la rehabilitación, por varios motivos que son necesarios conocer para evitar su repetición:

- Como consecuencia de la limitación de la deducción por inversión en vivienda habitual a las rentas bajas, los contribuyentes con una base imponible superior a 24.107,20 euros anuales no disfrutaban de beneficio fiscal en IRPF por rehabilitar sus viviendas.

- La limitación de la base máxima de la deducción a 9.040 euros anuales provocaba que el coste de adquisición de la vivienda agotara la deducción. En consecuencia, los ciudadanos que estuvieran satisfaciendo durante el periodo impositivo cantidades por adquisición de vivienda por un importe superior a 9.040 euros (como límite máximo de base de deducción), habían agotado la deducción.

El Real Decreto-Ley 6/2010, de 9 de abril, creó una deducción por obras de mejora con una limitación temporal, que finalizó el 31 de diciembre de 2012, aunque pueden seguir practicando la deducción las personas físicas 
que hayan pagado las cantidades relativas a las obras de rehabilitación antes del 1 de enero de 2013, siempre que la rehabilitación esté terminada antes del 1 de enero de 2017.

Por su parte, algunas CCAA han regulado, en ejercicio de sus competencias sobre la vivienda, una deducción por rehabilitación de viviendas. Podemos citar a Cataluña (Real Decreto-Ley 1/2008, art. 3). La CCAA de Murcia tiene establecida una deducción del $10 \%$ de las inversiones realizadas en ejecución de proyectos de instalación de recursos energéticos procedentes de las fuentes de energía renovables que se citan: solar térmica y fotovoltaica, y eólica. No puede superar los 1.000 euros anuales.

En todo caso, actualmente, debería existir en España una deducción por rehabilitación que supusiera un ahorro fiscal sobre un porcentaje de los gastos efectuados en actuaciones de rehabilitación.

Al igual que en el ámbito del IVA, el primer problema que nos encontramos es delimitar las actuaciones de rehabilitación. Si el propio concepto de "rehabilitación" es difuso, cuando se proyecta sobre el campo fiscal se convierte en etéreo.

En España existen, al menos, dos conceptos de rehabilitación en el Derecho tributario: uno en el ámbito del IRPF (art. 55.5 RIRPF, que no ha sido derogado, a pesar de que la deducción sí lo ha sido) y otro en el ámbito del IVA. El primero entiende como obras de rehabilitación aquellas que han sido calificadas o declaradas como actuación protegida en materia de rehabilitación de vivienda en los términos previstos en el RD 801/2005 (esto es, las mejoras en la accesibilidad, en la eficiencia energética, y en la seguridad estructural y la estanqueidad frente a la lluvia) y las obras que tengan por objeto principal la reconstrucción estructural de la vivienda. Esta última expresión (que tuviera por objeto principal la reconstrucción estructural) constituía una remisión por parte de la LIRPF a la Ley reguladora del IVA, que contenía una definición de rehabilitación en este sentido estructural. Sin embargo, como ya ha sido expuesto, el Real Decreto-Ley 6/2010 ha ampliado el concepto de rehabilitación estructural a efectos del IVA, por lo que consideramos que dicha ampliación debería recogerse también a efectos del IRPF, con la finalidad de seguir manteniendo la coherencia conceptual entre los dos impuestos.

En todo caso, al menos deberían aprobarse beneficios fiscales a favor de la rehabilitación energética o la realizada en barrios degradados.

Por lo que respecta a la rehabilitación energética, debería consistir en un porcentaje de deducción en la cuota íntegra sobre un importe máximo de gastos realizados en actuaciones conducentes a la mejora de la eficiencia energética del inmueble destinado a vivienda habitual.

Así lo han establecido el Reino Unido y Francia. El primero ha aprobado la llamada Landlord's Energy Saving Allowance (LESA) (ITTOIA 2005, s.312-314 y Reglamento 2007 SI 2007/831), que puede suponer una deducción en el impuesto sobre la renta de los propietarios que realizaron, antes del 6 de abril de 2015, actuaciones de mejora energética de la vivienda, como, por ejemplo, el aislamiento de paredes y suelos o el aislamiento del sistema de agua caliente. El gasto máximo deducible es 1.500 libras por vivienda.

Por su parte, Francia ha desarrollado una deducción (Crédit d'impôt) por gastos en la vivienda a favor de la calidad medioambiental (Dépenses en faveur de la qualité environnementale de l'habitation principa- 
le, regulado en el Code General des Impôts, art. 200 quarter). Es importante detenernos en este beneficio fiscal porque sería muy aconsejable su implantación en España: los propietarios e inquilinos de vivienda habitual pueden beneficiarse de una deducción en su Impuesto sobre la renta (Impôt sur le revenue) por los gastos soportados por la mejora de la calidad medioambiental de su vivienda.

Las actuaciones que generan el derecho a la deducción en Francia son, entre otras, la adquisición de calderas de condensación, de material de aislamiento térmico y de aparatos de regulación de calefacción, el gasto de equipamiento de producción de energía eléctrica o de recuperación y tratamiento de aguas pluviales.

En todo caso, deben cumplirse las siguientes condiciones:

a) El inmueble debe de estar en Francia.

b) Debe destinarse a vivienda habitual del propietario o del inquilino y haberse adquirido con una anterioridad superior a dos años. Si el gasto lo realiza el arrendador, puede disfrutar de la deducción siempre que hayan sido propietarios durante los dos años anteriores a la rehabilitación y se comprometan a alquilar el inmueble como vivienda habitual durante cinco años a personas que no pertenezcan a su unidad familiar. Como puede apreciarse, el beneficio fiscal no se limita a propietarios que viven en el inmueble, sino que se extiende a contribuyentes que alquilen el inmueble, siempre que el inquilino lo dedique a su vivienda habitual.

c) El conjunto de gastos no puede superar la suma de 8.000 euros por persona $-\mathrm{O}$ 16.000 euros si se trata de un matrimonio(más 400 euros por persona a cargo) por un periodo de cinco años consecutivos desde el 1 de enero de 2005 hasta el 31 de diciembre de 2015. Es decir, si la vivienda habitual está en alquiler, el límite de gastos es de 8.000 euros para el periodo comprendido entre el 1 de enero de 2009 y el 31 de diciembre de 2015.

Junto a la rehabilitación energética, debería potenciarse especialmente la rehabilitación de barrios degradados. En palabras de la Exposición de Motivos del Plan Estatal 2013-2016, los programas en torno a la rehabilitación y la regeneración y renovación urbanas "se diseñan con el objetivo de permitir a las ayudas que incorpora salir de los estrictos límites de las viviendas, para entrar en el contexto de los edificios, de los barrios y de la propia ciudad considerada en su conjunto". Como se mencionaba al principio de este documento, es particularmente importante evitar la existencia de barrios degradados en los que se aglutinen sectores de la población en riesgo de exclusión social, pues su inserción educativa, social y laboral pasa necesariamente por su inserción residencial.

En Francia, la llamada Loi Malraux prevé la aplicación de un porcentaje de deducción sobre los gastos efectuados de rehabilitación (incluidos los seguros y los gastos de gestión) en edificios ubicados en determinadas zonas urbanas siempre que se den las siguientes condiciones:

a) Que los inmuebles se destinen al alquiler y tengan como objeto la vivienda habitual o un uso profesional por parte del inquilino (Code General des Impôts, artículo 199).

b) Los beneficiarios sean personas físicas residentes en Francia.

c) La operación debe tener como objetivo la rehabilitación completa del edificio ubicado en la zona protegida, aunque se permite la restauración de parte del edificio.

d) El propietario debe comprometerse a alquilar el inmueble durante 9 años de forma 
continuada y debe alquilarse en el plazo de

12 meses desde el final de los trabajos.

El límite de la base de la deducción es de 100.000 euros anuales, sobre los que se aplica un porcentaje que varía entre el $22 \%$ y el $30 \%$, dependiendo de la zona en la que se encuentre el inmueble. Si el propietario incumple las condiciones, debe devolver el beneficio.

\section{Referencias}

\section{Bibliográficas}

Casado Ollero, G. (1998). "Los fines no fiscales de los tributos en el ordenamiento español”, en Comentarios a la Ley General Tributaria y Líneas para su reforma. Homenaje a Don Fernando Sainz de Bujanda I. Madrid: Instituto de Estudios Fiscales.

Falcón y Tella, R. (2008). “El RD Ley 2/2008, de 21 de abril (y III): Rehabilitación de edificaciones”, en Quincena fiscal, $\mathrm{n}^{\circ} 12$.

\section{Normatividad}

Code General des Impôts.

Exposición de la Ley de Rehabilitación, Regeneración y Renovación Urbanas.

Ley $7 / 2012$, de 29 de octubre.

Real Decreto 233/2013, de 5 de abril.

Real Decreto-Ley 20/2012, de 13 de julio.

Real Decreto-Ley 6/2010, de 9 de abril.

Loi 2012-1510 du 29-12-12.

\section{Doctrina especializada}

Applying the EPBD to improve the Energy Perfomance Requirements to Existing Buildings -ENPER EXIST, WP4: Roadmap for energy efficiency measures/policies in the existing building sector", coordinado por el Centre Scientifique et Technique du Batiment (CSTB).

Consultation paper. Review of existing legislation on VAT reduced rates", European Commission, TAXUD/D1 $\mathrm{D} / 24232$.

Informe "La Rehabilitación del Parque Residencial Existente en la Unión Europea y otros países europeos", XVIII Reunión Informal de Ministros responsables de vivienda de la Unión Europea, Toledo, 21 de julio de 2010.

RDGT 11/9/2006 v1818-06, RTEAC 12 de enero de 2000, 18 de febrero de 2000, 17 de marzo de 2003.

VAT ACT 1994, Section 29A. Notice 708/6 (noviembre 2011).

Communication from the Commission to the European Council. A European Economic Recovery Plan, Commission of the European Communities, Bruselas 26.11.2008. COM (2008).

Reduced VAT rates: Draft agreement with a view to responding to the European Council, Council of the European Union, 02.03.2009.

ITTOIA 2005, s.312-314 y Reglamento 2007 (SI 2007/831). 